\title{
UMA VISÃO SOBRE A CONSTRUÇÃO DIALÓGICA DA IDENTIDADE DO PROFESSOR DE ENSINO SUPERIOR
}

\author{
Isabela Vieira Barbosa ${ }^{1}$ \\ Marcia Regina Selpa Heinzle ${ }^{2}$ \\ Jessica Reinert dos Santos ${ }^{3}$
}

\begin{abstract}
Resumo
As identidades docentes são campo de grandes pesquisas nos estudos atuais sobre educação. Nesse sentido, o presente artigo busca analisar como os constructos identitários acerca do papel de ser professor de ensino superior ocorrem, através da perspectiva dos docentes que atuam nesse campo profissional. Para atingir o objetivo proposto por este artigo, a geração de dados se deu através da seleção e entrevista de professores universitários que cursam o primeiro ano do curso de Mestrado em Educação em uma universidade particular situada no sul do Brasil através da utilização de técnicas de complemento para a geração dos dados. Após a geração dos dados, realizamos as análises da materialidade linguística tendo como base teórica principal os estudos de Vygotsky (2001), levando em consideração a constituição das identidades que emergem dos relatos dos professores. A análise também se deu através dos estudos identitários (HALL, 2014; WOODWARD, 2014) e sobre a identidade e o fazer docente (GATTI, 1996). Nossos dados apontam que a identidade do professor ocorre nas construções diárias que enfrenta na profissão docente, além de trazer consigo suas experiências prévias vividas na esfera familiar, ou até mesmo escolar, nos tempos em que era aluno. É possível observar através das entrevistas, as marcas deixadas pelo ensino ao longo de todos os anos acadêmicos, das influências prévias, das vivências familiares e extracurriculares.
\end{abstract}

Palavras-chave: Ensino superior. Identidade. Professor. Relações dialógicas.

\section{A VIEW ON THE DIALOGICAL IDENTITY CONSTRUCTION OF THE HIGHER EDUCATION TEACHER}

\begin{abstract}
Teaching identities are a field of great research in current studies on education. In this sense, this article seeks to analyze how the identity constructs about the role of being a teacher of higher education occur, from the perspective of teachers who work in this professional field. In order to achieve the objective proposed by this article, the generation of data took place through the choice and interview of university professors who attend the first year of the Master's Degree in Education at a private university located in the south of Brazil using techniques complement for data generation. After generating the data, we carried out the analysis of linguistic materiality based on Vygotsky's (2001) studies, taking into account the constitution

\footnotetext{
${ }^{1}$ Universidade Regional de Blumenau (FURB), Blumenau - Santa Catarina - Brasil. Mestra em Educação pela Universidade Regional de Blumenau - FURB. Doutoranda em Educação pela Universidade Regional de Blumenau (FURB). ORCID <https://orcid.org/0000-0003-1939-572>. E-mail: miss.vieira@gmail.com.

${ }^{2}$ Universidade Regional de Blumenau (FURB), Blumenau - Santa Catarina - Brasil. Doutora em Educação pela Universidade Estadual de Campinas (UNICAMP). É docente do quadro permanente do Departamento de Educação e do Programa de Pós-graduação em Educação da FURB. ORCID <https://orcid.org/0000-0002-2299-8065>. Email: marciaselpa@gmail.com.

${ }^{3}$ Universidade Regional de Blumenau (FURB), Blumenau - Santa Catarina - Brasil. Mestre em Educação pela Universidade Regional de Blumenau - FURB. ORCID <https://orcid.org/0000-0002-6082-1615>. E-mail: jereinertfurb@gmail.com.
} 


\section{Linguagens - Revista de Letras, Artes e Comunicação - ISSN 1981- 9943 \\ Blumenau, v. 13, n. 2, p. 351-367, maio/ago. 2019 \\ DOI: http://dx.doi.org/10.7867/1981-9943.2019v13n2p351-367}

of the identities that emerge from the teachers' reports. The analysis also took place through identity studies (HALL, 2014; WOODWARD, 2014) and about identity and teaching (GATTI, 1996). Our data indicate that the teacher's identity occurs in the daily constructions that he faces in the teaching profession, in addition to bringing with him his previous experiences lived in the family, or even school, in the times when he was a student. Through the interviews, it is possible to observe the marks left by teaching throughout all academic years, previous influences, family and extracurricular experiences.

Keywords: Higher education. Identity. Teacher. Dialogical relations.

\section{INTRODUÇÃO}

A profissão docente na instituição de ensino superior vem sendo discutida numa visão sistemática sobre a constituição desse profissional por meio de graus de competências e saberes próprios dos espaços da academia (CUNHA, 2006). Embora muitas pesquisas apresentem a profissão do professor como um conglomerado homogêneo de profissionais, com pensamentos e ideologias congêneres, cada um traz consigo sua individualidade que forma um grupo heterogêneo de professores, com suas motivações e expectativas frente à profissão docente (GATTI, 1996).

O docente, portanto, é um ser que se constitui a partir de sua formação, da sua experiência e dos discursos que profere, e nesse sentido, podemos compreender as identidades “em locais históricos e institucionais específicos, no interior de formações e práticas discursivas singulares, por estratégias e iniciativas específicas" (HALL, 2014, p.109). Ou seja, as identidades docentes se formam a partir do meio social específico no qual o sujeito se insere, nesse caso, as instituições de ensino superior, e suas particularidades linguísticas exigidas para inserção nesse meio. É nas singularidades que as diferenças se formam, logo "a identidade é, assim, marcada pela diferença" (WOODWARD, 2014, p.9).

Nosso objetivo com esse artigo é o de analisar como os constructos identitários acerca do papel de ser professor de ensino superior ocorrem, através da perspectiva dos docentes, sujeitos dessa pesquisa. Assim, iniciaremos este artigo apresentando os entornos metodológicos que nos guiaram para a geração dos dados passando, em seguida, para a análise dos dados que puderam ser interpretadas a partir das narrativas de nossos sujeitos. Por último, apresentaremos nossas considerações acerca da pesquisa e as referências utilizadas ao longo do texto.

\section{PERCURSOS DA PESQUISA}




\section{Linguagens - Revista de Letras, Artes e Comunicação - ISSN 1981- 9943 \\ Blumenau, v. 13, n. 2, p. 351-367, maio/ago. 2019 \\ DOI: http://dx.doi.org/10.7867/1981-9943.2019v13n2p351-367}

Para atingir o objetivo proposto, inicialmente, escolhemos professores universitários que cursam o primeiro ano de Mestrado em Educação em uma universidade situada no sul do Brasil e, concomitantemente, atuam em instituições de ensino superior (IES) da região. Além disso, buscamos selecionar os professores formados em diferentes áreas para compreendermos como esses diferentes profissionais veem a profissão de ser professor de IES. Dessa escolha, surgiram dois professores que se encaixavam nos critérios estabelecidos. O professor A é formado em Educação Física, já o professor B tem como formação inicial Pedagogia e atua na área de Educação Especial.

Após a escolha, realizamos a geração dos dados através das técnicas de complemento, partindo dos pressupostos de Vergara (2006). Optamos por esse tipo de técnica, considerando a possibilidade de o sujeito ser levado a revelar motivações, crenças e sentimentos que poderiam, ou não, serem declarados através de perguntas mais direcionadas partindo de métodos de entrevistas estruturadas ou questionários com a formulação de perguntas fechadas.

Vale a pena ressaltar que utilizamos a expressão geração de dados baseados no que diz Mason (2002), ao compreender o pesquisador como construtor ativo do conhecimento, partindo de suas posições epistemológicas. Assim, os dados não estão prontos para serem recolhidos, mas sim, parte da habilidade do pesquisador com suas fontes para que os dados sejam gerados através da relação dialógica estabelecida entre o objeto e pesquisador.

As possibilidades para a utilização da técnica de complemento podem ser diversas, como quadrinhos, sentenças ou parágrafos. Nessa situação, optamos pela escolha de uma frase. A frase que buscamos resposta foi: "Ser professor de ensino superior é...". Como os horários disponíveis dos professores para realização da entrevista eram curtos, resolvemos dispor a eles a possibilidade de nos enviar por outros meios escritos suas respostas frente a nossa proposta. O professor A escolheu enviar-nos sua resposta através de gravação de áudio por um aplicativo de telefonia móvel, e, por conseguinte, realizamos a transcrição desta na íntegra. Já o professor B optou por nos enviar sua resposta através de correio eletrônico.

Fizemos a escolha de não mencionar o nome da universidade na qual estudam os professores e optamos, também por utilizar pseudônimos para preservar a identidade destes.

Após a geração dos dados, realizamos as análises da materialidade linguística tendo como base teórica principal os estudos de Vygotsky (2001), levando em consideração a constituição das identidades que emergem dos relatos dos professores.

\section{O FIO CONDUTOR TEÓRICO QUE GUIA NOSSOS PASSOS}




\section{Linguagens - Revista de Letras, Artes e Comunicação - ISSN 1981- 9943 \\ Blumenau, v. 13, n. 2, p. 351-367, maio/ago. 2019 \\ DOI: http://dx.doi.org/10.7867/1981-9943.2019v13n2p351-367}

Ao conduzir nossa pesquisa fundamentamos nossas análises em autores que encontram na dialeticidade o aporte para respaldar seus pensamentos. Compreendendo o sujeito como um sujeito sócio-histórico, Freire $(1987 ; 1996)$ desponta como o principal referencial desta obra.

Vygotsky (2001) estabelece que a consciência é um processo mediatizado pelo signo, e que o sujeito é constituído nas atividades executadas através das conexões sociais estabelecidas através dos signos. Com Freire (1987) complementamos tal pensamento, ao afirmar que essa incorporação dos signos pelos sujeitos, que estabelece a tomada de consciência de Vygotsky é mediada pelo mundo. Freire e Vygotsky indicam que ao se educarem, os homens se educam em uma relação dialógica (VYGOTSKY, 2001) através dos signos preexistentes no mundo.

Desta forma os autores convergem para um pensamento que defende a constituição do sujeito como um sujeito sócio-histórico, "[...] inserido num permanente movimento de procura, faz e refaz constantemente o seu saber" (FREIRE, 1981, p. 47) e que o "[...] comportamento do homem é formado pelas peculiaridades e condições biológicas e sociais de seu crescimento" (VYGOTSKY, 2001, p. 63).

Assim, "os indivíduos são afetados, de diferentes modos, pelas muitas formas de produção nas quais eles participam - também de diferentes maneiras; ou seja, os sujeitos são profundamente afetados por signos e sentidos produzidos nas (e nas histórias das) relações com os outros" (SMOLKA, 2000, p. 31, grifo nosso).

\section{O QUE DIZEM OS DOCENTES}

A academia é o espaço em que professor e aluno se encontram para dialogar sobre suas visões de mundo, suas experiências, suas convicções e crenças. É o local no qual professor e aluno tem a oportunidade de se expressarem e reconstruírem suas práticas profissionais com base nas discussões propostas. Outra característica do espaço acadêmico é sua dinamicidade, tanto da prática oral quanto escrita, uma vez que ambas se entrelaçam e emergem das relações sociais estabelecidas no contato social acadêmico. Os discursos de nossos professores vêm ao encontro com os dizeres acima ao trazerem que:

(1) “[...] é um ambiente que é dinâmico, que não é estático, que tá sempre em movimento tá sempre exigindo bastante [...]" (PROFESSOR A - grifos nossos). 


\section{Linguagens - Revista de Letras, Artes e Comunicação - ISSN 1981- 9943 \\ Blumenau, v. 13, n. 2, p. 351-367, maio/ago. 2019 \\ DOI: http://dx.doi.org/10.7867/1981-9943.2019v13n2p351-367}

(2) “[...] você entra na sala de aula, fecha a porta e é como se você se transportasse para outro lugar, as coisas se transformam diante daquelas quatro paredes, pensamentos fervilhando, perguntas incessantes, curiosidades, dúvidas, todos sedentos por respostas" (PROFESSOR B - grifos nossos).

Essa dinâmica da qual os professores falam diz respeito a exigência feita ao professor pela busca ao conhecimento que os alunos apresentam. Freire (2014, p.33) destaca "a curiosidade como inquietação indagadora, como inclinação ao desvelamento de algo, como pergunta verbalizada ou não, como procura de esclarecimento, como sinal de atenção que sugere alerta, faz parte integrante do fenômeno vital". Fenômeno este que insere o aluno como ativo no processo de aprendizagem, que o instiga ainda mais pela busca do conhecimento, que o deixa inquieto, frente às indagações que emergem do contexto no qual se situa, conforme traz o excerto (2) ao afirmar que os alunos vêm ao ambiente acadêmico "sedentos por respostas".

O movimento dialógico que aflora dos dizeres dos professores pode ser compreendido como a relação entre homem e mundo através de artefatos culturais. Nesse caso, a linguagem, se constituí pelo homem como "um signo mediador por excelência, pois ela carrega em si os conceitos generalizados e elaborados pela cultura humana" (REGO, 2014, p.42) para que se possa estabelecer comunicação e compreensão entre locutor e interlocutor. Assim, podemos reconhecer, com base nas interpretações emergentes dos excertos acima, que nossos sujeitos compreendem o ensino como espaço de interação e construção de conhecimento (COLAÇO; FISCHER, 2015). A partir dos excertos analisados, podemos depreender que a identidade do professor emerge a partir do momento em que nos dispomos a observá-los dentro de sala de aula, das suas relações sociais, sendo estas, constitutivas de seu ser (GATTI, 1996).

A profissão docente não se constitui somente na individualidade do sujeito, mas traz consigo suas experiências e vivências anteriores ao ingresso à carreira de professor, pelas vozes sociais que antecederam o sujeito e que o constituem (FARACO, 2009). Rossi (2004, p. 22) destaca que a identidade dos docentes é também influenciada pela "maneira como os profissionais avaliam a construção do conhecimento e a si próprios", demonstrando que o professor está sujeito não só as influências externas, mas está também, em constante transformação e construção. Em consonância com tais dizeres, o professor A afirma que "desde a minha vivência escolar" sempre teve muita afinidade à docência, vindo em consonância com o professor B ao trazer que, adentrando ao meio universitário, rememora sua fase de acadêmico e relembra suas expectativas diante dos seus antigos e atuais professores. Nesses dizeres 


\section{Linguagens - Revista de Letras, Artes e Comunicação - ISSN 1981- 9943 \\ Blumenau, v. 13, n. 2, p. 351-367, maio/ago. 2019 \\ DOI: http://dx.doi.org/10.7867/1981-9943.2019v13n2p351-367}

podemos constatar que a identidade de professor integra as vivências que os sujeitos perpassaram dentro e fora da escola, antes de se tornarem educadores.

Podemos observar também que "os professores são os construtores das vias pelas quais as experiências traduzidas em conhecimentos estruturados e organizados circulam interpessoas e intergerações" (GATTI, 1996, p. 89), ou seja, seus discursos são carregados das experiências passadas e proliferam em suas práticas em sala de aula, onde as experiências individuais integram a experiência do outro que o transforma e, ao interagir com o outro, o transformará também, caracterizando um ciclo em espiral. Nesse sentido, podemos concluir que "as palavras do professor têm muito poder, pois serão levadas a diante como palavras ao vento, somos formadores de opinião, referência e muitas vezes modelos que eles pretendem seguir quando se identificam e se apaixonam por nossas práticas" (PROFESSOR B). E que diante de tal relevância na prática, de poder influenciar, de servir como exemplo, Freire destaca que "Não há pensar certo fora de uma prática testemunhal que re-diz em lugar de desdizê-lo" (FREIRE, 2015 , p. 36, grifo do autor). Tendo em vista que ser um exemplo para o aluno representa respeitá-lo como sujeito no mundo, tratá-lo numa relação eu-tu, e não objetificá-lo (FREIRE, 2015). Mas ao mesmo tempo, demonstrar através dos exemplos, para que ações e palavras não se contradigam no exercício da prática docente.

Dessa maneira, os ecos que ressoam da voz do professor nos chamam a atenção para uma postura ética a qual o educador deve assumir. Ambos os professores concordam que a profissão docente no ensino superior requer planejamento, disciplina, organização, para que o decorrer das aulas possa acontecer da melhor maneira possível, além de posicionar-se ideologicamente sobre a concepção de aluno que se quer formar, conforme observado nos excertos trazidos no parágrafo anterior. Nesse viés reflexivo, podemos atentar ao que diz Freire (2014, p.68 - grifos do autor)

[...] toda prática educativa demanda a existência de sujeitos, um que, ensinando, aprende, outro que, aprendendo, ensina, daí o seu cunho gnosiológico; a existência de objetos, conteúdos a serem ensinados e aprendidos; envolve o uso de métodos, de técnicas, de materiais; implica, em função de seu caráter diretivo, objetivo, sonhos, utopias, ideias. Daí a sua politicidade, qualidade que tem a prática educativa de ser política, de não poder ser neutra.

São essas escolhas políticas, conforme Freire (2014), que influenciam os professores a assumir uma identidade dentro de sala, uma compreensão sobre o conteúdo e uma postura profissional. "A identidade permeia o modo de estar no mundo e no trabalho" (GATTI, 1996, p.85). A educação conforme ressalta o próprio Freire (2015), é um ato político, e desta forma 


\section{Linguagens - Revista de Letras, Artes e Comunicação - ISSN 1981- 9943 \\ Blumenau, v. 13, n. 2, p. 351-367, maio/ago. 2019 \\ DOI: http://dx.doi.org/10.7867/1981-9943.2019v13n2p351-367}

se faz necessário o posicionamento do professor diante de suas ideologias que irão perpassar a sua identidade dentro da sala de aula.

(3) "[...] você não sabe o que te espera, dá um friozinho bom na barriga e quando percebemos passaram-se 4 horas de aula, você falou o tempo todo e não conseguiu alcançar metade do seu planejamento" (PROFESSOR B - grifo nosso).

Desta forma, destacamos a preocupação do professor B, ao citar que ao planejar nem sempre o professor consegue atingir todo o conteúdo programado, pois a vivência em sala de aula é, e deve ser sempre dinâmica, proporcionando aos alunos uma experiência de aprendizado, e não apenas uma reprodução mecânica. Isso exige do profissional uma adaptação às diferentes situações impostas pelo momento, pelas diferenças culturais e sociais dos alunos e pelos imprevistos. Outro aspecto importante a ser ressaltado são as vivências trazidas pelo professor em sua prática. Durante a jornada acadêmica, o (agora) professor, já desempenhou o papel de aluno e traz consigo essa bagagem que reflete em sua prática pedagógica. Ambos os papeis constroem a identidade do professor e essa vivência anterior é colocada em sua prática docente, analisada e repensada por meio do constante diálogo ideológico e social que emerge do contexto acadêmico e do professor em sua formação de identidade e pertencimento.

Compreende-se também, que assim como a construção identitária do profissional docente está em constante transformação, os alunos que tanto contribuem para esse crescimento pessoal e profissional, também são sujeitos em construção e passando por uma constante desconstrução como destacado pelo professor A.

(4) "Eu acho muito bacana, essa oportunidade na faculdade, fazer o pessoal entender que esse caos, ele é normal, ele é importante, é necessário no nosso encaminhamento de vida" (PROFESSOR A - grifo nosso).

Por tanto, Freire (2015, p. 42) destaca que a necessidade de "propiciar as condições com que os educandos em suas relações uns com os outros e com o professor ou a professora ensaiam a experiência profunda de assumir-se." Levando esta tarefa de se assumir para além dos ambientes acadêmicos, afinal tanto as identidades docentes quanto as identidades discentes, irão se constituir em um constante diálogo, pois conforme o mesmo autor assume, "não há docência sem discência" (FREIRE, 1996, p. 12). 


\section{Linguagens - Revista de Letras, Artes e Comunicação - ISSN 1981- 9943 \\ Blumenau, v. 13, n. 2, p. 351-367, maio/ago. 2019 \\ DOI: http://dx.doi.org/10.7867/1981-9943.2019v13n2p351-367}

Na carreira docente, se faz necessária também, a busca constante pelo conhecimento, dispondo de maior gnose aos estudantes, para que compreendam a dinâmica social e suas implicações. Em cada contexto, a "leitura e escrita diferenciam-se segundo contextos sociais, exercendo papéis diversos na vida de grupos ou indivíduos específicos" (SOARES, 2015, p.37). No grupo específico dos professores, a pesquisa se faz relevante no cotidiano profissional, pois como o professor B aborda que "ser professor [...] é dedicar-se incessantemente a pesquisa, a busca [...]". Pesquisar significa conhecer aquilo que ainda é desconhecido, é desvelar o que não se sabe, é descontruir e reconstruir significações. É trazer os alunos para perto de si nesse movimento dialógico entre conhecimento-mundo-sujeito, assumindo uma postura de guia frente ao novo, aprendendo e ensinando, em dinâmica concomitante, pois "pesquiso para conhecer o que ainda não conheço e comunicar e anunciar a novidade" (FREIRE, 2014, p.30$31)$.

A necessidade de continuar pela busca do conhecimento vem em consonância com os dizeres do professor A: "ser professor universitário é também, é uma oportunidade de você continuar sempre aprendendo né”, pactuando com a afirmação de Freire (2015, p. 31) de que “não há ensino sem pesquisa e pesquisa sem ensino". Freire (2015) ressalta que enquanto se faz o exercício contínuo de ensinar, busca-se e reaprende-se com o fazer, sempre numa eterna construção entre fazer-pensar o fazer. Desta forma, o autor destaca a necessidade de uma postura crítica-reflexiva do professor, que busque analisar sua prática, para planejá-la, e ao planejá-la esteja constantemente analisando e refletindo sobre a mesma.

A partir desse dizer, podemos nos remeter a outro pensamento do autor relacionado com esse movimento reflexivo, que o autor chamaria de inacabamento. Enquanto seres inseridos em uma sociedade, devemos nos compreender como seres históricos e inacabados. Históricos uma vez que, nossa cultura e nossa realidade se dão através das construções históricas que perpassaram nossos ancestrais e nos perpassam para compreendermos o meio em que vivemos. Inacabados, pois nos encontramos em constantes modificações, em constante transformação, assim como a prática em sala de aula.

Através desse entendimento de historicidade e inacabamento, compreendemos nossa inconclusividade em e com uma realidade que também está inacabada pela sua historicidade. Assim, a educação se torna um que-fazer permanente, em razão de homem e realidade serem objetos inacabados. Logo, a educação se (re) faz na práxis, uma vez que "para ser tem que estar sendo" (FREIRE, 1987, p. 42). 


\section{Linguagens - Revista de Letras, Artes e Comunicação - ISSN 1981- 9943 \\ Blumenau, v. 13, n. 2, p. 351-367, maio/ago. 2019 \\ DOI: http://dx.doi.org/10.7867/1981-9943.2019v13n2p351-367}

\section{A CONSTRUÇÃO DOS SENTIDOS DA PROFISSÃO DOCENTE}

Ao falarmos da construção da identidade docente, é necessário abordar a importância da construção dos sentidos nesse processo de interação entre alunos, professores, universidades e os mais diversos artefatos culturais. Afinal, será através desta interação entre esses sujeitos, objetos e os diferentes ambientes culturais aos quais eles estão expostos que os sentidos serão construídos. Através de "[...] um processo ativo e dinâmico, em que sujeitos interagem por meio da linguagem" (FISCHER; PELANDRÉ, 2010, p.576).

Mas, ao situarmos a construção desses sentidos, encontramos em nossos professores afirmações que transpassam os ambientes acadêmicos e penetram suas identidades, tornam-se parte não só dos discursos proferidos, mas da visão que eles passam a ter da educação, do ensino e principalmente do processo de aprender. Ao destacar que ensinar "[...] é muito mais que a remuneração que você recebe", o professor A conversa com a afirmação de Lima (2012, p. 163, grifo nosso), que destaca que "a aprendizagem real se situa apenas em ambientes culturais específicos, onde há interação com os artefatos culturais e com outros seres humanos". Reforçando a afirmação que é necessária essa relação entre sujeito-sujeito e sujeito-mundo para que a aprendizagem real possa acontecer.

Ao aprofundarmos esta interação com os outros seres humanos, e a forma tão aparente na qual apresenta-se proferida nos discursos dos professores aqui analisados, notamos a importância do contato com o outro, a confiança e a necessidade da relação dialógica com os outros. Estes contatos tornar-se-ão imprescindíveis para a construção da identidade docente (THIVES, 2009; RADVANSKEI, 2015). Essa relação dialógica irá ocorrer, pois “o docente raramente atua sozinho. Ele se encontra em interação com outras pessoas, a começar pelos alunos" (SILVA, 2009, p. 26).

Paralelamente a esta interação surge o sentimento e a necessidade pela busca de outros saberes docentes, de aprimoramento pessoal, pois ao encontrarem "diferentes fontes sociais, os professores movimentam-se discursivamente nos espaços de formação, possibilitando a construção de novas identidades, como também a estabilização de outras, construídas no campo pessoal". (THIVES, 2009, p.105). 


\section{Linguagens - Revista de Letras, Artes e Comunicação - ISSN 1981- 9943 \\ Blumenau, v. 13, n. 2, p. 351-367, maio/ago. 2019 \\ DOI: http://dx.doi.org/10.7867/1981-9943.2019v13n2p351-367}

(4) "Quando tudo está ruim, seu dia foi difícil, cheio de problemas para resolver, você entra na sala de aula, fecha a porta e é como se você se transportasse para outro lugar" (PROFESSOR B).

(5) “[...] eu vejo assim como uma oportunidade de ajudar nessa formação profissional para que o pessoal, eles valorizem mesmo a profissão, que saiam bem capacitados, que eles realmente lutem para que essa profissão se engrandeça, tenha reconhecimento" (PROFESSOR A).

Os docentes entrevistados, como podemos ver no excerto 5, trazem a tona discussões além da complementação "ser professor é...", nesse sentido, podemos observar as associações estabelecidas por estes docentes em sua prática, e a relação intrínseca entre suas identidades pessoais e profissionais.

Em conformidade com tais discursos, Moita Lopes (2002, p. 32) afirma que "é a presença do outro com o qual estamos engajados no discurso que, em última análise, molda o que dizemos e, portanto, como nós percebemos à luz do que o outro significa para nós”. Por isto, nesta relação entre professor e aluno, muitas vezes a construção da identidade docente é feita também pela influência e contato com os acadêmicos. Os sucessos e insucessos, a forma como os alunos se espelham na imagem do professor e as críticas recebidas, constituem parte deste processo. Assim sendo, demonstra-se que o que é levado em consideração, é onde ocorre essas interações (TARDIF, 2002) ou como Silva (2009, p. 25) destaca, esses contatos que ocorrem no ambiente acadêmico "atribuem novos significados a sua formação teóricoacadêmica ao estarem em contato com a sala de aula real em pleno exercício do ofício, atuando como professor".

Além disso, se faz necessária "à compreensão do ensino como realidade social" (PIMENTA, 2000, p. 18) para que através dessa compreensão possa se desenvolver nos acadêmicos-professores a capacidade de investigar a própria ação. E a partir desta, “constituírem e transformarem os seus saberes-fazeres docentes, num processo contínuo de construção de suas identidades como professores" (PIMENTA, 2000, p. 18). Afinal, ao longo da nossa análise, podemos notar que diversos autores abordam que a experiência "evidencia que a trajetória pessoal, a experiência enquanto aluno são pré-profissionais" (SILVA, 2009, p. 24) influencia e preenche um espaço nessa constituição identitária profissional. 


\section{Linguagens - Revista de Letras, Artes e Comunicação - ISSN 1981- 9943 \\ Blumenau, v. 13, n. 2, p. 351-367, maio/ago. 2019 \\ DOI: http://dx.doi.org/10.7867/1981-9943.2019v13n2p351-367}

(6) "É um misto de sensações, boas e ruins, de prazeres e de dificuldades, de incertezas, medos, e sem dúvida na maioria das vezes felicidades e realizações” (PROFESSOR B).

No excerto 6, o professor B destaca que é "um misto de sensações", e podemos tentar traduzir essas sensações descritas, como alguns dos sentidos, que serão vividos verdadeiramente nesse tempo experienciado, não no nosso tempo cronológico. Serão através desses sentidos e das experiências concretas, vivenciadas dentro do ambiente escolar, das salas de aula e no contato com os alunos, que irá permitir a construção de sentidos que proporcionem a construção de um eu profissional. (TARDIF, 2002), pois "as experiências vivenciadas no ambiente escolar são estruturantes para a formação, atuação e aprendizagem docente" (SILVA, 2009, p. 27).

(7) "E eu consegui trabalhar com o que eu gosto. Que é difícil hoje trabalhar alguém trabalhar com o que gosta, não tendo uma visão muito comercial, assim de ganhar um alto salário" (PROFESSOR A).

(8) “eu sou professor universitário é porque eu quero” (PROFESSOR A).

(9) "Você até encontra um ou outro professor ali que, percebe que eles consideram a faculdade como um bico, como um extra, e só que ai você percebe que esses, sofrem muito na hora de lecionar" (PROFESSOR A).

(10) “A falta de comprometimento, as más intenções, podem sim decepcionar, mas não devem nunca tirar o professor do seu caminho" (PROFESSOR B).

O lado negativo da identidade docente também é destacado pelos entrevistados. Em (8), o professor deixa claro que a escolha de seguir a carreira docente se deu a partir de sua vontade, de seus anseios à profissão. Essa realização só se deu por inteiro, a partir de suas experiências que foram construindo a sua identidade profissional, pois “é a partir dos saberes práticos ou experienciais que os professores expressam seus próprios valores" (SILVA, 2009, p. 26)

O professor B, no trecho (10), ressalta que há "falta de comprometimento" por parte de alguns profisssionais da área da educação. Porém, reiteramos que "é nessa experiência de experiências de ensino que o aluno-mestre irá validar, negar, desenvolver e consolidar os 


\section{Linguagens - Revista de Letras, Artes e Comunicação - ISSN 1981- 9943 \\ Blumenau, v. 13, n. 2, p. 351-367, maio/ago. 2019 \\ DOI: http://dx.doi.org/10.7867/1981-9943.2019v13n2p351-367}

saberes teóricos" (SILVA, 2009, p. 25, grifo nosso). Entretanto, como o autor ressalta muitas vezes o docente irá negar os saberes. O professor que por falta de comprometimento, se nega a oportunidade de desenvolver e consolidar seus conhecimentos, ele nega não apenas o que considera desnecessário ou dispensável a sua prática, ele nega e renega o próprio conhecimento que poderia the ser essencial para validar sua prática. Para desenvolver-se não só como profissional docente, mas como ator social e impossibilita a consolidação de conhecimentos prévios junto aos novos conhecimentos. Muitas vezes tornando-se ultrapassado (FREIRE, 1996).

Ensinar “[...] supõe aprender a ensinar, ou seja, aprender a dominar progressivamente os saberes necessários à realização do trabalho docente" (TARDIF, 2002, p.20), significa buscar os conhecimentos específicos, mas não se submeter apenas aos conhecimentos teóricos. Ensinar é ter os conhecimentos necessários para o exercício de sua profissão, mas aprender a lidar com o outro, desenvolver a habilidade de ensinar, assim podendo também exercer o ato de ensinar.

O professor intervém num meio ecológico complexo, num cenário psicossocial vivo
e mutável, definido pela interação simultânea de múltiplos fatores e condições. Nesse
ecossistema o professor enfrenta problemas de natureza prioritariamente prática, que,
quer se refiram a situações individuais de aprendizagem ou a formas de
comportamento de grupos, requerem um tratamento singular, na medida em que se
encontram fortemente determinados pelas características situacionais do contexto e
pela própria história da turma enquanto grupo social. (PÉREZ GÓMEZ, 1992, p.102)

O professor A, no trecho (11), a seguir, traz um pensamento semelhante ao discutido pelo professor B no trecho (10). Ao versar sobre os problemas cotidianos e a dificuldade diária da prática docente emergem dos docentes, como podemos observar quando o professor A reforça a necessidade do comprometimento do profissional com a sua práxis. Pérez Gómez (1992) na fala anterior, também traz sobre essas dificuldades práticas, que podem ocorrer tanto na aprendizagem, quanto nos relacionamentos no ambiente acadêmico, um desafio nos dias atuais. Entretanto, o autor também destaca que para isso surge a necessidade de um tratamento adequado para tais situações, pois as mesmas são representativas do momento e do local de cada grupo social, por isso o professor encontrará em diferentes ambientes ações diferentes. Novamente, exige-se do professor mais do que uma capacidade de adaptação a tais diferenças, a reflexão sobre sua prática, para que saiba, entre outras coisas, adequar-se e conciliar tais diferenças entre o ensino e o convívio dialógico entre os atores sociais.

Para tal, defendemos que "ao professor também é indispensável à sensibilidade sobre suas experiências e sobre sua interação com os demais sujeitos desse processo de aprendizagem" (SILVA, 2009, p. 25), pois não se pode existir no mundo, sem a presença do 


\section{Linguagens - Revista de Letras, Artes e Comunicação - ISSN 1981- 9943 \\ Blumenau, v. 13, n. 2, p. 351-367, maio/ago. 2019 \\ DOI: http://dx.doi.org/10.7867/1981-9943.2019v13n2p351-367}

outro. Não se pode educar nem para o outro, nem o outro, mas sim com o outro (FREIRE, 2014, grifo nosso).

(11) "se você não ta convicto daquilo que você quer fazer, o professor universitário sofre bastante. Então, é uma coisa assim que eu, existe os problemas cotidianos, que tu, por querer esta ali acaba conseguindo lidar com isso" (PROFESSOR A).

(12) "somos desafiados todos os dias e o caminho o qual escolhemos nem sempre é o mais fácil, aliás, poucas vezes será fácil, pois a vida não é mesmo fácil" (PROFESSOR B).

O professor B destaca na fala (12) as dificuldades encontradas ao longo do caminho. Aqui reiteramos que "a atividade docente não é exercida sobre um objeto, sobre um fenômeno a ser conhecido ou uma obra a ser produzida" (TARDIF, 2002, p.49-50). Lidar com o outro, é constantemente adaptar-se e readaptar-se. É uma rede de "interações com outras pessoas, num contexto onde o elemento humano é determinante e dominante e onde estão presentes símbolos, valores, sentimentos, atitudes, que são passíveis de interpretação e decisão [...]" (TARDIF, 2002, p.49-50). São diferentes crenças, valores e sentimentos expressos, interpretações passíveis de divergências. São diferentes atores sociais vivendo, aprendendo e convivendo conjuntamente, mas ao mesmo tempo se desafiando e impondo sua presença no mundo. Essas interações, possibilitam desafios e obstáculos ao longo da carreira docente, bem como da própria formação discente do professor.

Desta forma, o trecho (11) do professor A serve como um complemento para os desafios colocados pelo professor B no trecho (12). Quando este aborda as dificuldades encontradas caso o professor não esteja convicto do que pretende fazer. O professor A retoma a necessidade da reflexão, da decisão e da atuação responsável do docente sobre sua influência sobre os discentes. A importância de sua atuação não só para o ensino e aprendizado de seus alunos, mas para com a própria educação e a formação de sujeitos. $\mathrm{O}$ professor $\mathrm{B}$ também ressalta a importância e o desafio de tal missão, no trecho (12), falando que “[...] o caminho o qual escolhemos nem sempre é o mais fácil [...]" mas ambos concordam que o desafio é mais do que válido. 


\section{Linguagens - Revista de Letras, Artes e Comunicação - ISSN 1981- 9943 \\ Blumenau, v. 13, n. 2, p. 351-367, maio/ago. 2019 \\ DOI: http://dx.doi.org/10.7867/1981-9943.2019v13n2p351-367}

(13) “cada semestre é um semestre diferente, é uma turma diferente, é vivências diferentes, e isso é vida, isso que anima isso que engrandece isso que... que existe a busca de você estar sempre informado, de estar buscando mais capacitação, isso te capacita também" (PROFESSOR A).

Conforme destacado pelo professor A, na fala anterior, o ambiente acadêmico é um ambiente vivo e rico de experiências e oportunidades. Por isso, Nunes (2001, p.27) destaca que "Considera-se assim que este, [o professor] em sua trajetória, constrói e reconstrói seus conhecimentos conforme a necessidade de sua utilização, suas experiências, seus percursos formativos e profissionais, etc.".

Ao longo dos dizeres vamos percebendo que o docente vai se transformando enquanto tal a partir de suas experiências enquanto aluno da educação básica, acadêmico na graduação. A partir dessas experiências, "os professores vão incorporando certas habilidades sobre seu saber-fazer e saber-ser, ou seja, é com a própria experiência que o aluno de outrora, o qual possuía apenas saberes teóricos, aprende a ser professor” (SILVA, 2009, p. 25). É a partir de minha experiência enquanto sujeito social que me torno profissional.

\section{CONSIDERAÇÕES FINAIS}

Ao longo deste trabalho tivemos a oportunidade de compreender um pouco mais sobre a construção da identidade docente a partir de dois professores de nível superior. Através das vozes dos nossos professores, compreendemos que a construção dos sentidos se dá por meio da vivência e da convivência com o outro e as diferentes oportunidades produzidas no dia a dia acadêmico.

O professor em nível superior, tal como diversos outros profissionais, frequenta o ambiente acadêmico no nível médio e no nível superior em busca de uma formação acadêmica, uma preparação para o mercado de trabalho. Mas, a verdadeira preparação para a atuação docente ocorre antes e depois desse período. Percebem-se marcas deixadas pelo ensino ao longo de todos os anos na escola de educação básica, das influências prévias do professor enquanto aluno. O professor é graduado na universidade, qualificado para exercício de sua profissão e adquire diversos conhecimentos teóricos válidos e necessários para a prática docente. Porém, é a convivência com o ambiente acadêmico, as experiências físicas e emocionais que vivencia neste ambiente que o marcam profundamente e o preparam para o exercício constante da 


\section{Linguagens - Revista de Letras, Artes e Comunicação - ISSN 1981- 9943 \\ Blumenau, v. 13, n. 2, p. 351-367, maio/ago. 2019 \\ DOI: http://dx.doi.org/10.7867/1981-9943.2019v13n2p351-367}

mesma, pois são "esses saberes da experiência que se caracterizam por serem originados na prática cotidiana da profissão, sendo validados pela mesma" (THERRIEN, 1995, apud NUNES 2001, p.31).

Durante a análise da fala dos sujeitos, emerge fortemente que o professor se constitui de suas relações também enquanto aluno. A prática pedagógica desenvolvida por seus professores durante os anos de estudo e convivência na educação básica, trazem reflexões e análise de como este professor que ser, quer exercer sua profissão, com base na interlocução com demais sujeitos professores que perpassaram sua vida e nela deixaram marcas positivas e negativas que permitem a reflexão e reconstrução da prática docente e, consequentemente, da sua identidade enquanto professor. Outro aspecto emergente dessa análise foi a construção do ser professor também por meio da interação com os demais colegas professores que constituem o meio social no qual o docente está inserido. Essa relação, que traz consigo ideologias e reflexões, permite o professor olhar para si e repensar suas ações pedagógicas, repensando e reconstruindo assim, sua identidade. Desse modo, percebe-se que o professor se reconstitui diariamente por meio de suas interações, trazendo aspectos do presente e do passado que irão influenciar a identidade do professor no futuro.

\section{REFERÊNCIAS}

COLAÇO, Silvania Faccin; FISCHER, Adriana. Letramentos acadêmicos em um programa de iniciação à docência: modos de interação em práticas pedagógicas. Linguagem \& Ensino, Pelotas, v.16, n.1, p. 1-25, maio/jul. 2015.

CUNHA, Maria Isabel. Docência na universidade, cultura e avaliação institucional: saberes silenciados em questão. Revista Brasileira de Educação, v. 11, n. 32, p.258-371, maio/ago 2006.

FISCHER, Adriana; PELANDRÉ, Nilcéa Lemos. Letramento acadêmico e a construção de sentido nas leituras de um gênero. Perspectiva, v. 28, n. 2, p.569-599, 14 jul. 2011. Universidade Federal de Santa Catarina (UFSC).

FREIRE, Paulo. Pedagogia da autonomia. Rio de Janeiro: Paz e Terra, 1996. 143p.

FREIRE, Paulo. Pedagogia do oprimido, 17a ed. Rio de Janeiro: Paz e terra, 1987. 107p.

GATTI, Bernadetti. A. Os professores e suas identidades: o desvelamento da heterogeneidade. Caderno de Pesquisa, São Paulo, n. 98, p. 85-90, ago. 1996.

HALL, Stuart. Quem precisa da identidade? In: SILVA, T. T. Identidade e diferença: a perspectiva do Estudos Culturais. 15. ed. Petrópolis: Vozes, 2014. p. 103-133. 
LIMA, Alberto José Ferreira de. Letramento digital e letramento informacional na literatura nacional e internacional em língua inglesa. 2012. 204 f. Dissertação (Mestrado) Curso de Educação, Universidade Federal da Paraíba, João Pessoa - Pb, 2012.

MOITA LOPES, Luiz Paulo. Identidades fragmentadas: a construção discursiva de raça, gênero e sexualidade em sala de aula. Campinas: Mercado de Letras, 2002.

NUNES, C. M. F. Saberes docentes e formação de professores: um breve panorama da pesquisa brasileira. Educação e Sociedade, ano XXII, n.74, p.27-42. abr. 2001.

PÉREZ GÓMEZ, Angel. O pensamento prático do professor - A formação do professor como Profissional Reflexivo. In: NÓVOA, A. (Org.). Os professores e a sua formação. Lisboa: Instituto de Inovação Educacional e autores, 1992. p.93-114.

PIMENTA, Selma Garrido. Formação de professores: identidades e saberes da docência. In: Didática e formação de professores: percursos e perspectivas. São Paulo: Cortez, 1998. p.15-34.

RADVANSKEI, Sônia de Fátima. A construção da docência de alfabetizadoras de Araucárias sob a perspectiva de dialogicidade e responsividade: Possibilidades e influências da formação continuada. 2015. 234 f. Dissertação (Mestrado) - Curso de Educação, Universidade Federal do Paraná, Curitiba, 2015.

REGO, Tereza Cristina. Vygotsky: uma perspectiva histórico-cultural da educação. 25. ed. Petrópolis: Vozes, 2014. 139p.

ROSSI, Eliane Cavalher Solano. $A$ construção do conhecimento e da identidade do professor de inglês. Dissertação de Mestrado. Programa de Pós-Graduação em estudos da Linguagem. Universidade Federal de Londrina, 2004

SILVA, Marilda. Complexidade da formação de professores: saberes teóricos e saberes práticos [online]. São Paulo: Editora UNESP; São Paulo: Cultura Acadêmica, 2009. 114 p. ISBN 978-85-98605-97-5. Disponível em: <http://books.scielo.org $>$. Acesso em: 28 de novembro de 2015.

SMOLKA, Ana Luiza Bustamante. O (im)próprio e o (im)pertinente na apropriação das práticas sociais. Cad. CEDES. 2000, vol.20, n.50, pp. 26-40

SOARES, Magda. Língua escrita, sociedade e cultura: relações, dimensões e perspectivas. In: SOARES, Magda. Alfabetização e letramento. 6. ed. Contexto: São Paulo, 2015. p. 27-45.

TARDIF, Maurice. Saberes Docentes e Formação Profissional. 3.ed. Trad. Francisco Pereira. Petrópolis, RJ: Vozes, 2002.

THIVES, Patrícia Ferreira. As vozes sociais que constituem os discursos dos professores em relação a sua identidade docente. Dissertação de Mestrado. Universidade Regional de Blumenau, 2009, 110 fls.

VYGOTSKY, Lev Semenovitch. Psicologia Pedagógica. São Paulo. Martins Fontes, 2001. 
WOODWARD, Kathryine. Identidade e diferença: uma introdução teórica e conceitual. In: SILVA, T. T. (org.). Identidade e diferença: a perspectiva dos Estudos Culturais. 15. ed. Petrópolis: Vozes, 2014. p.7-72. 